\title{
PERSEPSI MASYARAKAT LOKAL TERHADAP USAHA TANI KARET (Hevea brasiliensis) DI DESA LAJA KECAMATAN TANAH PINOH BARAT KABUPATEN MELAWI
}

\author{
(Local Community Perception of Rubber Farmer (Hevea brasiliensis) in Laja Village Tanah \\ Pinoh Barat District Melawi Regency)
}

\author{
Dedang Kharismanto, Sofyan Zainal, H A Oramahi \\ Fakultas Kehutanan Universitas Tanjungpura. Jalan Imam Bobjol Pontianak 78124 \\ Email : Dedangkharismanto@gmail.com
}

\begin{abstract}
Rubber farming has been in demand by the people of Laja Village since 1990's as a livelihood by utilizing shifting fields within the forest. Some people's income from the results of rubber farming is very large, especially during the dry season, where people tap into rubber sap every day. Rubber prices experienced a decline that was felt by rubber farmers and in the rainy season the people could not tap rubber sap, the people were forced to find alternative jobs, such as gold mining and other jobs. This situation certainly raises different perceptions of society. This study aims to determine the public perception of rubber farming and analyze the relationship between knowledge, income and cosmopolitan factors. This study uses descriptive and associative surveys with interview techniques and the questionnaire contains a number of questions posed to respondents, collecting data using random purposive sampling. Data analysis using descriptive analysis of the chi square test and inferential analysis using the nonparametric statistical test of the Kendall Tau correlation. The number of respondents in the study were 72 people. The results of this study indicate that public perceptions tend to be positive, moderate level of knowledge, low income level, high cosmopolitan level. There is a positive and significant relationship between the level of knowledge and perception, and there is no significant and no relationship between income levels and cosmopolitan with community perceptions.
\end{abstract}

Keywords: Local community Perception, Rubber Farmers

\section{PENDAHULUAN}

Tanaman karet (Hevea brasiliensis) termasuk dalam famili Euphorbiaceae, dan dengan nama lain seperti rambung, getah, gota, kejai ataupun hapea. Karet merupakan salah satu komoditas perkebunan yang penting sebagai sumber devisa non migas bagi Indonesia, sehingga memiliki prospek yang cerah. Upaya peningkatan produktivitas tanaman karet terus dilakukan terutama dalam bidang teknologi budidaya dan pasca panen (Damanik et al. 2010). Berdasarkan peraturan Menteri Kehutanan Republik
Indonesia Nomor :p.62/menhut-ii/2011 Tentang pedoman pembangunan hutan tanaman berbagai jenis mengemukanan bahwa tanaman karet diperbolehkan menjadi salah satu tanaman pada Hutan Tanaman Industri. Jenis tanaman tahunan berkayu yang kayunya dapat dimanfaatkan untuk bahan baku industri dalam pembangunan hutan tanaman berbagai jenis antara lain meliputi karet, kelapa, dan sawit serta dapat dikembangkan menjadi IUPHHBK-HT. Perkebunan karet di negara ini mencapai luas total 3,65 juta hektar. Karena prospek industri karet positif, 
telah ada peralihan dari perkebunanperkebunan komoditi seperti kakao, kopi dan teh, menjadi perkebunan-perkebunan kelapa

sawit dan karet. Jumlah perkebunan karet milik petani kecil telah meningkat, sementara perkebunan pemerintah dan swasta telah berkurang, kemungkinan karena perpindahan fokus ke kelapa sawit (BPS, 2017). Masyarakat di Desa Laja usaha tani karet telah diminati oleh masyarakat dari sejak tahun 1990' an sebagai mata pencaharian dengan memanfaatkan ladang berpindah didalam hutan.

Menurut masyarakat menyadap getah karet merupakan pekerjaan yang ringan dan tidak memerlukan waktu yang lama dalam menyadap getah karet, biasanya masyarakat di Desa Laja menyadap karet mulai dari jam 06.00 pagi sampai jam 10.00. Menurut Yulius (2012) masyarakat cenderung memiliki persepsi positif terhadap usaha tani karet, hal ini menunjukan bahwa masyarakat tersebut telah merasakan dampak positif dari usaha tani karet, yang paling utama adalah dari segi pendapatannya. Faktor pengetahuan, pendapatan dan kosmopolitan sangat mempengaruhi persepsi masyarakat, semakin tinggi pengetahuan maka semakin besar pendapatan atas suatu pekerjaan dan semakin banyak informasi yang seseorang ketahui atas suatu pekerjaan semakin baik pula persepsi seseorang terhadap usaha atau pekerjaan dalam hal ini yaitu usaha tani karet. Beberapa masalah yang sering dihadapi oleh masyarakat dalam usaha tani karet, yaitu harga karet mengalami penurunan yang sangat dirasakan oleh petani karet dan pada musim hujan tiba masyarakat tidak bisa menyadap getah karet. Hal tersebut tentunya berpengaruh terhadap perekonomian dan jumlah produksi getah karet yang dihasilkan oleh masyarakat pada waktuwaktu tertentu, khususnya masyarakat lokal di Desa Laja yang mengandalkan usaha tani tanaman karet pada areal bekas perladangan sebagai mata pencaharian utama. Harga sembako yang terus melonjak naik, untuk menghadapi persoalan demikian masyarakat terpaksa mencari pekerjaan alternatif, seperti bekerja menambang emas dan pekerjaan lainnya. Keadaan ini tentu saja menimbulkan persepsi dalam masyarakat lokal di Desa Laja selaku penyadap getah karet. Guna mengetahui persepsi masyarakat terhadap usaha tani karet, maka perlu dilakukan penelitian mengenai persepsi masyarakat lokal terhadap usaha tani tanaman karet. Penelitian ini bertujuan untuk mengetahui persepsi masyarakat terhadap usaha tani karet dan menganalisis hubungan antara pengetahuan,tingkat pendapatan dan tingkat kosmopolitan dengan persepsi masyarakat lokal di Desa Laja Kecamatan Tanah Pinoh Barat Kabupaten Melawi tentang usaha tani karet.

\section{METODE PENELITIAN}

Penelitian ini dilaksanakan di Desa Laja Kecamatan Tanah Pinoh Barat Kabupaten Melawi. Pengumpulan data dilakukan dalam waktu 2 minggu di lapangan, dimulai tanggal 6 Agustus-20 Agustus 2018. Penelitian ini menggunakan metode survey yang bersifat deskriptif dan asosiatif dengan teknik wawancara dan alat bantu kuesioner berupa formulir daftar pertanyaan yang diajukan kepada sejumlah responden. Metode pengambilan sampel penelitian dengan menggunakan metode Purposive Random Sampling. Penentukan besarnya ukuran sampel dalam penelitian ini akan dihitung dengan 
rumus slovin (Riduwan, 2005) sebagai berikut :

$$
\mathrm{ni}=\frac{\mathrm{Ni}}{1+\mathrm{Ne}^{2}}
$$

Keterangan :

ni $=$ Jumlah sampel ke $\mathrm{i}$

$\mathrm{Ni}=$ Jumlah populasi $\mathrm{ke} \mathrm{i}$

i $=1,2,3,4$.

e $=$ Batas toleransi kesalahan (Persen

Kesalahan)
Kriteria masyarakat yang akan dijadikan responden secara purposive random sampling yaitu: (a). Kepala Keluarga (b). Petani Karet (c). Umur minimal 20 tahun (sudah berkeluarga) (d). Sehat jasmani dan rohani (e). Bisa Baca Tulis. Berdasarkan perhitungan menggunakan rumus slovin didapat total responden 72 kepala keluarga, untuk lebih jelas, jumlah responden dapat dilihat pada Tabel 1 .

Tabel 1. Jumlah Populasi Dan Sampel Responden Rencana Penelitian (Total Population And Sample Of Research Respondents)

\begin{tabular}{llcc}
\hline No & Dusun & Jumlah KK & Jumlah Sampel \\
\hline 1 & Tanjung Permai & 88 & 25 \\
2 & Bina Baru & 90 & 25 \\
3 & Poring Jawa & 78 & 22 \\
\hline & Jumlah & 256 & 72
\end{tabular}

Data yang dikumpulkan meliputi : (1) data primer yaitu data mengenai persepsi masyarakat lokal terhadap usaha tani karet (Hevea brasiliensis) di Desa Laja, yang akan dihubungkan berdasarkan tingkat pengetahuan, pendapatan dan tingkat kosmopolitan, (2) data sekunder yaitu data penunjang yang berhubungan dengan keadaan lokasi penelitian, diperoleh dari instansi terkait yang menunjang hasil penelitian. Data tersebut ditabulasikan dan kemudian dianalisis menggunakan Chi Square dan untuk mengetahui hubungan variabel terikat dan variabel bebas dilakukan menggunakan Uji Statistik Non Parametrik Uji Korelasi Kendall Tau dengan rumus seperti berikut (Priyatno, 2012) :

$$
\mathbf{r}=\frac{\sum A-\sum B}{N(N-1)} /
$$

Keterangan :

r $\quad$ : Koefisien korelasi kendall tau

A : Jumlah rangkaian atas

B : Jumlah rangkaian bawah

$\mathrm{N} \quad$ : Jumlah gagasan sampel 


\section{HASIL DAN PEMBAHASAN}

Karakteristik Responden Berdasarkan Persepsi

Tabel 2. Frekuensi Responden Berdasarkan Persepsi (Frequency Of Respondents Based On Perception)

\begin{tabular}{clcc}
\hline No & Persepsi & Frekuensi & Persentase $(\%)$ \\
\hline 1 & Positif & 37 & 51,39 \\
2 & Netral & 8 & 11,11 \\
3 & Negatif & 27 & 37,50 \\
\hline & Jumlah & 72 & 100 \\
\hline
\end{tabular}

Sumber : Hasil Analisis Data Primer Penelitian di Desa Laja Agustus 2018

Tabel 2 menunjukan bahwa 37 mempunyai persepsi negatif terhadap responden (51,39\%) mempunyai usaha tani karet di Desa Laja. Persepsi persepsi positif terhadap usaha tani karet di Desa Laja Kecamatan Tanah Pinoh Barat Kabupaten Melawi, 8 responden $(11,11 \%)$ mempunyai persepsi netral terhadap usaha tani karet dan $27(37,50 \%)$ responden yang masyarakat terhadap usaha tani karet sangat positif, masyarakat yang memiliki persepsi yang positif yaitu mereka yang menganggap usaha tani tersebut sebagai mata pencaharian sehari-hari untuk menemuhi kebutuhan.

Karakteristik Responden Berdasarkan Tingkat Pengetahuan

Tabel 3. Frekuensi Responden Berdasarkan Tingkat Pengetahuan (Frequency of Respondents Based on knowledge level )

\begin{tabular}{clcc}
\hline No & Persepsi & Frekuensi & Persentase (\%) \\
\hline 1 & Tinggi & 30 & 41,67 \\
2 & Sedang & 15 & 20,83 \\
3 & Rendah & 27 & 37,50 \\
\hline & Jumlah & 72 & 100 \\
\hline
\end{tabular}

Sumber : Hasil Analisis Data Primer Penelitian di Desa Laja Agustus 2018

Berdasarkan hasil Penelitian dari 72 responden yang terdapat di Desa Laja menujukan bahwa 30 responden (41,67\%) mempunyai tingkat pengetahuan tinggi, 15 resonden (20,83\%) mempunyai tingkat pengetahuan sedang dan 27 responden $(37,50 \%)$ mempunyai tingkat pengetahuan yang rendah terhadap usaha tani karet di Desa Laja. Hal ini menunjukan bahwa pengetahuan masyarakat di Desa Laja tinggi. semakin tinggi tingkat pengetahuan masyarakat terhadap karet maka persepsi cendrung positif. 


\section{Karakteristik Responden Berdasarkan Tingkat Kosmopolitan}

Tabel 4. Frekuensi Responden Menurut Tingkat Kosmopolitan (Frequency Of Respondents Based on Cosmopolitan)

\begin{tabular}{clcc}
\hline No & Persepsi & Frekuensi & Persentase (\%) \\
\hline 1 & Tinggi & 34 & 47,22 \\
2 & Sedang & 14 & 19,45 \\
3 & Rendah & 24 & 33,33 \\
\hline & Jumlah & 72 & 100 \\
\hline
\end{tabular}

Sumber : Hasil Analisis Data Primer Penelitian di Desa Laja Agustus 2018

Berdasarkan hasil Penelitian dari $72 \quad(33,33 \%) \quad$ mempunyai tingkat responden yang terdapat di Desa Laja kosmopolitan yang rendah terhadap menujukan bahwa 34 responden usaha tani karet di Desa Laja. Tingkat $(47,22 \%)$ mempunyai tingkat kosmopolitan masyarakat sangat tinggi, kosmopolitan tinggi, 14 resonden hal ini menujukan bahwa masyarakat $(19,45 \%)$ mempunyai tingkat mendapatkan pengetahuan secara luas kosmopolitan sedang dan 24 responden tentang usaha tani karet.

Karakteristik Responden BerdasarkanTingkat Pendapatan

Tabel 5. Frekuensi Responden Menurut Tingkat Pendapatan(Frequency Of Respondents Based on income level )

\begin{tabular}{ccccc}
\hline No & $\begin{array}{c}\text { Kategori } \\
\text { Pendapatan }\end{array}$ & Pendapatan (RP/Bulan & Frekuensi & Persentase (\%) \\
\hline 1 & Tinggi & $\geq 1.859 .213$ & 33 & 45,83 \\
2 & Sedang & 1.617 .176 s/d 1.859 .213 & 6 & 8,34 \\
3 & Rendah & $<1.617 .176$ & 33 & 45,83 \\
\hline & Jumlah & 72 & 100 \\
\hline
\end{tabular}

Sumber : Hasil Analisis Data Primer Penelitian di Desa Laja Agustus 2018

Berdasarkan hasil pengamatan data dalam penelitian sebagaimana diuraikan dalam tabel 10, diperoleh frekuensi kelompok tingkat pendapatan responden masyarakat di Desa Laja memiliki tingkat pendapatan yang bervariasi berdasarkan sampel penelitian terdapat 33 responden $(45,83 \%)$ tergolong dalam kelompok pendapatan lebih dari $\mathrm{Rp}$ 1.859.213.- per bulan, 6 responden $(8,34 \%)$ tergolong dalam kelompok pendapatan antara $\mathrm{Rp} 1.617 .176 \mathrm{~s} / \mathrm{d} \mathrm{Rp}$ 1.859.213 per bulan, dan 33 responden
$(45,83 \%)$ termasuk dalam kelompok pendapatan di bawah Rp 1.617.176 per bulan. Pendapatan masyarakat di Desa Laja tergolong rendah dari UMR Kabupaten Melawi, hal ini disebabkan harga karet yang masih rendah.

\section{Analisis Deskripstif}

Persepsi masyarakat lokal terhadap usaha tani karet (Hevea brasiliensis) di Desa Laja dianalisa dengan analisis deskriptif dengan uji statistik deskriptif menggunakan tabulasi frekuensi. Berdasarkan olahan data primer hasil 
pengamatan lapangan diperoleh kategori frekuensi persepsi responden terhadap usaha tani karet (Hevea brasiliensis) yaitu positif sebanyak 37 responden $(51,39 \%)$, netral sebanyak 8 responden $(11,11 \%)$, dan negatif sebanyak 27 responden $(37,50 \%)$. Frekuensi persepsi masyarakat lokal terhadap usaha tani karet (Hevea brasiliensis) disajikan pada Tabel 6.

Tabel 6. Frekuensi Responden Berdasarkan Persepsi (Frequency Of Respondents Based On Perception)

\begin{tabular}{clcc}
\hline No & Persepsi & Frekuensi & Persentase $(\%)$ \\
\hline 1 & Positif & 37 & 51,39 \\
2 & Netral & 8 & 11,11 \\
3 & Negatif & 27 & 37,50 \\
\hline & Jumlah & 72 & 100
\end{tabular}

Sumber : Hasil Analisis Data Primer Penelitian di Desa Laja Agustus 2018

Tabel 7. Uji statistik deskriptif Chi Square (Descriptive Statistical Test Chi Square)

\begin{tabular}{ccccccc}
\hline No & Alternatif Pilihan & $f_{0}$ & $f_{h}$ & $\left(f_{0-} f_{h}\right)$ & $\left(f_{0-} f_{h}\right)^{2}$ & $\left(\frac{f_{0-} f_{h}}{f h}\right)^{2}$ \\
\hline 1 & Positif & 37 & 24 & 13 & 169 & 7,04 \\
2 & Netral & 8 & 24 & -16 & 256 & 10,67 \\
3 & Negatif & 27 & 24 & 3 & 9 & 0,37 \\
\hline & Jumlah & 72 & 72 & 0 & & 18,08 \\
\hline
\end{tabular}

Sumber : Hasil Analisis Data Primer Penelitian di Desa Laja Agustus 2018

Hasil Uji Statistik Deskriptif (Uji

Chi Square) diperoleh nilai Chi Square

(r) hitung pada taraf kepercayaan 5\% sebesar 18,08 lebih besar dari uji chi square tabel sebesar 5,59 (Hasil uji Statistik deskriptif terlampir). Hal ini menunjukan bahwa terdapat perbedaan signifikan frekuensi persepsi masyarakat lokal terhadap usaha tani karet diDesa Laja dan persepsi masyarakat tersebut cendrung positif (Ha diterima dan $\mathrm{Ha}$ ditolak ). Hasil olahan data primer sebagaimana diuraikan pada Tabel 7 dan hasil uji statistik deskriptif dapat diinterprestasikan bahwa 72 responden penelitian sebagian 37 responden $(51,39 \%)$ cendrung persepsi positif terhadap usaha tani karet di Desa Laja.

Hasil Pengamatan dilapangan diperoleh informasi bahwa responden yang mempunyai persepsi positif terhadap usaha tani karet adalah masyarakat yang beranggap atau merasakan bahwa dengan melakukan usaha tani karet dapat memenuhi kebutuhan sehari-hari, dan kondisi ini akan berdampak positif terhadap peningkatan perekonomian masyarakat dengan bertani karet, masyarakat dapat penghasilan setiap bulan atau minggu. Kondisi ini terlihat dari 72 responden penelitian ini adalah petani karet. Menurut Yulius (2012) masyarakat cenderung memiliki persepsi positif terhadap usaha tani karet, hal ini menunjukan bahwa masyarakat tersebut telah merasakan dampak positif dari usaha tani karet, yang paling utama adalah dari segi pendapatannya.

Berdasarkan hasil data primer diperoleh bahwa tingkat persepsi 
masyarakat terhdapa usaha tani karet dipengaruhi oleh tingkat pengetahuan dan tingkat kosmopolitan. Pengetahuan sendiri dipengaruhi oleh faktor pendidikan oleh faktor pendidikan formal, pengetahuan sangat erat hubungannya dengan pendidikan, dimana diharapkan dengan pendidikan yang tinggi maka orang tersebut akan semakin luas pengetahuannya. Akan tetapi, perlu ditekankan bukan berarti seseorang yang berpendidikan rendah mutlak berpengetahuan rendah, hal ini mengingat bahwa peningkatan pengetahuan tidak mutlak diperoleh dari pendidikan formal saja, akan tetapi dapat diperoleh pendidikan non formal dan keterbukaan masyarakat dalam mencari dan menerima informasi baru. Responden tingkat pengetahuan tinggi yang memiliki persepsi positif yaitu masyarakat yang mempunyai wawasan yang luas , mempunyai pola pikir yang baik dan mau menerima berbagai informasi dari luar secara khusus mengenai usaha tani karet.

Responden yang tingkat pengetahuan sedang memiliki persepsi yang tinggi terhadap usaha tani karet ini menyatakan pengetahuan seseorang berpengaruh terhadap pandangan seseorang jika pengetahuan mereka rendah maupun sedang bukan berarti pemahaman mereka kurang akan tetapi masyarakat menilai berdasarkan apa yang mereka lihat, berdasarkan pengetahuan dan berdasarkan pengalaman yang mereka miliki.

Responden yang memiliki pengetahuan cenderung rendah memiliki persepsi yang negatif terhadap usaha tani karet ini menyatakan pengetahuan seseorang berpengaruh terhadap pandangan seseorang jika pengetahuan mereka rendah maupun sedang bukan berarti pemahaman mereka kurang akan tetapi masyarakat menilai berdasarkan apa yang mereka lihat, berdasarkan pengetahuan dan berdasarkan pengalaman yang mereka miliki. Menurut Milunardi (2014), pengetahuan adalah berbagai gejala yang ditemui dan diperoleh manusia melalui pengamatan akal dan pengetahuan seseorang dapat mempengaruhi pola pikir atau tingkat kesadaran, sikap atau perilaku seseorang terhadap kegiatan yang dilakukannya.

Tingkat pendapatan masyarakat terhadap usaha tani karet di Desa Laja yaitu $45,83 \%$ cendrung rendah dan persepsi cendrung negatif hal ini karenakan harga karet yang murah mengakibatkan pendapatan petani karet menjadi rendah, tetapi petani karet tetap melakukan usaha tani karet untuk memenuhi kebutuhan hidup sehari-hari.

Sedangkan responden dengan pendapatan tinggi memilik persepsi yang positif terhadap usaha tani karet karena responden merasakan banyak dampak yang positif dari hasil usaha tani karet salah satunya adalah menambah penghasilan.

Hasil wawancara terhadap 72 responden diperoleh informasi bahwa hanya beberapa saja yang masih ingin menambah lahan karet untuk meningkatkan penghasilan dan memanfaatkan sisa ladang berpindah untuk dijadikan kebun karet. Hal ini 
dikarenakan harga karet yang sekarang sangat murah dan banyak yang membiarkan lahan tersebut tidak ditanami tanaman karet. Masyarakat yang mempunyai persepsi cendrung netral adalah responden yang ragu-ragu untuk menentukan persepsi terhadap usaha tani karet. Hal ini dikarenakan masyarakat beranggapan bahwa hasil dari usaha tani karet untuk memenuhi kebutuhan hidup sehari-hari sangat kecil dan terkadang tidak mencukupi jika hanya mengandalkan dari usaha tanaman karet saja.

Ni'am dan Mussadun (2014) persepsi adalah proses penilaian seseorang/sekelompok orang terhadap objek, peristiwa, atau stimulus dengan melibatkan pengalaman-pengalaman yang berkaitan dengan objek tersebut. Persepsi masyarakat dalam melestarikan hutan dipengaruhi oleh seberapa aktif masyarakat dalam berinteraksi dengan hutan akibat dipengaruhi daya subjektif.
Persepsi ini pada gilirannya juga akan mempengaruhi penilaian mengenai status peringkat yang terkait pada suatu isu.

Persepsi cenderung negatif terhadap usaha tani karet disebabkan oleh responden bahwa usaha tani karet adalah suatu pekerjaan yang kurang bagus dari hasil wawancara yang diperoleh, masyarakat sangat dibebani kekhawatiran untuk terus melakukan usaha tani karet karena harganya yang terkadang tidak stabil (turun/naik nya harga).

\section{Analisis Inferensial}

Menganalisis variabel terikat dan variabel bebas dilakukan dengan korelasi Kendall Tau yang terdiri dari 1 (satu) Variabel terikat yaitu persepsi dan 3 (tiga) variabel bebas yaitu tingkat pengetahuan, tingkat pendapatan dan tingkat kosmopolitan. Hasil uji korelasi pearson variabel terikat dengan variabel bebas dapat dilihat pada Tabel 8 .

Tabel 8. Hasil Uji Korelasi Kendall Tau Hubungan Karakteristik Variabel Terikat dan Variabel Bebas.

\begin{tabular}{lllll}
\hline \multirow{2}{*}{ No } & Variabel Terikat Persepsi & \multicolumn{2}{c}{ Variabel Bebas } & Keterangan \\
& & Correlation & Sig (2-Tailed) & \\
\hline 1 & Pengetahuan & 1.000 & $0,000^{* *}$ & Signifikan \\
2 & Pendapatan & $-0,045$ & 0,679 & Tidak Signifikan \\
3 & Kosmopolitan & $-0,166$ & 0,120 & Tidak Signifikan \\
\hline \multicolumn{4}{l}{ Sumber : Hasil Analisis Data Primer Penelitian di Desa Laja Agustus 2018 } &
\end{tabular}

1. Hubungan Persepsi dengan Tingkat Pengetahuan

Hasil dari uji Statistik (uji korelasi Kendall Tau) sebagaimana diuraikan pada Tabel 8 diketahui nilai Sig. (2tailed) sebesar $0,000^{* *}$ dan nilai Correlation coefficient positif 1.000 . Nilai Sig $0,000 * *<0,050$, sehingga dapat disimpulkan bahwa terdapat hubungan yang positif dan signifikan antara tingkat pengetahuan dengan persepsi masyarakat terhadap usaha tani karet di Desa Laja . artinya semakin tinggi tingkat pengetahuan terhadap usaha tani karet maka persepsi masyarakat cenderung positif.

Berdasarkan hasil pengamatan diketahui bahwa tingkat pengetahuan 
masyarakat terhadap usaha tani karet $(41,67 \%)$ termasuk dalam kategori tinggi, sedangkan persepsi masyarakat terhadap usaha tani karet sebagian besar $(51,39 \%)$ termasuk dalam kategori positif. Bina (2006) menyatakan bahwa pengetahuan merupakan hasil dari tahu dan ini terjadi setelah melakukan penginderaan terhadap objek tertentu. Sebagian pengetahuan manusia berasal dari mata dan telinga. Hasil pengamatan di interprestasi bahwa tingkat pengetahuan masyarakat terhadap usaha tani karet tergolong sedang. Hal ini ditunjukan bahwa masyarakat yang memilih untuk melakukan usaha tani karet.

Responden dengan tingkat pengetahuan tinggi yaitu memiliki persepsi positif yaitu masyarakat yang menyadari bahwa karet merupakan salah satu komoditi pertanian yang penting dapat menunjang perekonomian negara karena menghasilkan devisa yang cukup besar dan responden tersebut mengetahui cara dalam mengusahakan tani karet agar dapat meningkatkan produksi, misalnya dengan penyiangan, pemupukan dan pengaturan jarak tanam. Sedangkan responden yang memiliki tingkat pengetahuan rendah cenderung memiliki persepsi negatif terhadap usaha tani karet namun hanya sedikit responden yang memiliki pengetahuan rendah yaitu 27 responden (37,50\%), hal ini mungkin dikarenakan masyarakat yang memiliki pengetahuan rendah tidak terlalu memahami tentang cara pengelolaan usaha tani karet agar mendapatkan hasil dan produksi. Dapat disimpulkan bahwa tingkat pengetahuan masyarakat yang tinggi dan sedang cenderung memiliki persepsi yang positif terhadap usaha tani karet.

Hasil penelitian ini sesuai dengan pendapat Sueca NP et al (2001) yang menyatakan tingkat pengetahuan masyarakat tentang sesuatu berpengaruh terhadap persepsi dan perilakunya, artinya semakin tinggi tingkat pengetahuan seseorang maka diharapkan persepsi dan peran serta perilakunya semakin bertambah baik.

2. Hubungan Persepsi Dengan Tingkat Pendapatan

Hasil uji statistik (uji korelasi kendall tau) sebagaimana diuraikan pada Tabel 8 diketahui nilai sig. (2tailed) sebesar 0,679 dan nilai correlation coefficent negatif $-0,045$. Nilai sig 0,679>0,050, sehingga dapat disimpulkan bahwa terdapat hubungan yang negatif dan tidak signifikan antara pendapatan masyarakat terhadap usaha tani karet di Desa Laja akan cenderung negatif hal ini menunjukan bahwa pendapatan masyarakat mempengaruhi persepsi masyarakat lokal terhadap usaha tani karet di Desa Laja.

Berdasarkan hasil olahan data primer diketahui tingkat pendapatan masyarakat $(45,33 \%)$ termasuk dalam kategori rendah, hal ini dikarenakan masyarakat tidak terlalu banyak merasakan dampak positif dari usaha tani karet dan responden memiliki pekerjaan yang lain yang hasilnya jauh lebih besar dari pada usaha tani karet. Hal ini tidak sejalan dengan hasil penelitian Husinsyah (2006) yang menyatakan bahwa karet salah satu 
komoditi pertanian yang penting yang dapat menunjang perekonomian negara karena menghasilkan pendapatan yang cukup besar.

Tingkat pendapatan responden termasuk dalam kategori cenderung rendah karena pekerjaan masyarakat dominan sebagai petani karet dengan rata-rata pendapatan kuramg dari $\mathrm{Rp}$. 1.617.176 per bulan, karena masih banyak pendapatan masyarakat diperoleh bukan berasal dari usaha tani karet,seperti menambang emas (PETI), beternak atau menanam sayur-sayuran, berdagang, pertukangan dan lainnya. Maka tingkat pendapatan tidak berhubungan dengan persepsi masyarakat lokal terhadap usaha tani karet di Desa Laja.

Berdasarkan SK Gubernur Kalimantan Barat Nomor : 561/DISNAKERTRANS/2018 tentang Penetapan Upah Minimum Kabupaten Melawi Tahun 2018 sebesar Rp 2,288,306.-/bulan, jika dilihat dari tingkat pendapatan responden masyarakat Desa Laja dibawah Upah Minimum Kabupaten Melawi pendapatan masyarakat rendah karena harga karet turun mempengaruhi rendahnya tingkat pendapatan. Hal ini sejalan dengan pendapatan Sarjono (2008) pendapatan adalah sejumlah penghasilan yang diterima oleh penduduk atas prestasi kerjanya selama beberapa periode tertentu, baik berupa harian, mingguan, bulanan serta tahunan.

3. Hubungan Persepsi Dengan Tingkat Kosmopolitan
Hasil uji statistik (uji korelasi kendall tau) sebagaimana diuraikan pada Tabel 8 diketahui nilai sig. (2tailed) sebesar 0,120 dan nilai correlation coefficent negatif $-0,166$. Nilai sig 0,120>0,050, sehingga dapat disimpulkan bahwa terdapat hubungan yang negatif dan tidak signifikan antara kosmopolitan masyarakat terhadap usaha tani karet di Desa Laja. Artinya semakin tinggi tingkat kosmopolitan maka persepsi cenderung positif.

Berdasarkan hasil olah data tingkat kosmopolitan masyarakat terhadap usaha tani karet cenderung tinggi $(47,22 \%)$ hal ini menunjukan bahwa semakin terbukanya seseorang untuk mencari dan menerima informasi atas suatu usaha atau pekerjaan maka semakin luas juga pengetahuan dan wawasan seseorang, sehingga seseorang dapat menilai baik dan buruknya suatu pekerjaan. Sedangkan responden dengan kosmopolitan rendah cenderung memiliki persepsi negatif terhadap usaha tani karet, hal ini dikarenakan kurang terbukanya seseorang untuk menerima dan mencari atas suatu usaha atau bekerja sehingga responden tersebut cenderung memiliki persepsi negatif terhadap suatu pekerjaan. Semakin tinggi tingkat kosmopolitan masyarakat akan memiliki kecenderungan yang besar untuk dapat menerima suatu objek atau sesuatu hal yang bersifat membangun.

Hasil penelitian ini sesuai dengan pendapat Budiono (2005) yang menyatakan kosmopolitan merupakan suatu wawasan dan pengetahuan yang luas. Terlihat bahwa disetiap kategori 
tingkat kosmopolitan responden mempunyai persepsi yang cenderung tinggi, hal ini menunjukan bahwa masyarakat berusaha untuk memperoleh informasi tentang usaha tani tanaman karet baik dari media elektronik seperti televisi, radio maupun dari surat kabar dan informasi-informasi yang di peroleh dari masyarakat sekitar tempat tinggal responden.

\section{Kesimpulan}

1. Persepsi masyarakat Lokal terhadap usaha tani karet ( Hevea brasiliensis) di Desa Laja cendrung Positif yaitu dengan frekuensi 37 dengan persentase $51,39 \%$.

2. Terdapat hubungan yang positif dan signifikan antara pengetahuan masyarakat dengan persepsi masyarakat lokal terhadap usaha tani karet. Terdapat hubungan yang negatif dan tidak signifikan antara tingkat pendapatan masyarakat dengan persepsi masyarakat lokal terhadap usaha tani karet. Terdapat hubungan negatif dan tidak signifikan antara tingkat kosmopolitan masyarakat dengan persepsi masyarakat lokal terhadap usaha tani karet.

\section{Saran}

1. Supaya harga karet tinggi masyarakat seharusnya menjaga kualitas karet dengan cara tidak mencampurkan bekas karet yang ditores dengan getah murni karet itu sendiri, sehingga dengan kualitas yang bagus bisa meningkat harga jual karet.

2. Diharapkan penelitian selanjutnya melihat dari faktor lainnya, seperti melihat dari luas kebun karet, harga, pembeli dan penampung serta kemudahan dalam menanam karet sehingga hasil penelitian ini akan lebih valid.

\section{UCAPAN TERIMAKASIH}

Penulis mengucapkan terimakasih kepada masyarakat Desa Laja Kecamatan Tanah Pinoh Barat Kabupaten Melawi yang telah mengizinkan melakukan penelitian di Desa tersebut dan telah memberikan respon yang sangat baik serta bersedia memberikan informasi dan ilmu yang berkaitan dengan penelitian sehingga penelitian ini berjalan dengan lancar tanpa suatu kendala apapun.

\section{DAFTAR PUSTAKA}

Bina K, Lestantyo D, Murtiningsih D. 2006. Hubungan Karakteristik Pekerja Dengan Praktik Penerapan Prosedur Keselamatan Kerja di PT. Bina Buna Kimia Ungaran. Fkm.Undip. Jurnal Promosi Kesehatan Indonesia. Vol.1.No.2.Diakses: 17 April 2018

Budiono. 2005. Kamus Lengkap Bahasa Indonesia. Surabaya. Karya Agung

Damanik S, Syakir M, Made T, Siswanto. 2010. Budidaya dan Pasca Panen Karet. Pusat Penelitian dan Pengembangan Perkebunan. Bogor.

Husinsyah. 2006. Kontrobusi Pendapatan Petani Karet (Hevea brasiliensis) Terhadap Pendapatan Petani Dikampung Mencimai Kecamatan Barong Tongkok Kabupaten Kutai Barat. EPP. Vol.3 (1): Halaman 9-21 [28 Maret 2018] 
Milunardi, Fahrizal Dan Iskandar. 2014. Partisipasi Masyarakat Sekitar Hutan Dalam Melestarikan Hutan Adat Sebagai Penyangga Sumber Air di Desa Menyabo Kecamatan Tayan Hulu Kabupaten Sanggau. Jurnal Hutan Lestari. Vol.02.No.02

Ni'am Al, Mussadun. 2014. Dampak Aktivitas Ekowisata di Pulau Karimunjawa Berdasarkan Persepsi Masyarakat. Junrnal Teknik Pwk. Volume 3.2:262273.Www.portal.Garuda.Com. Diakses: 27 April 2018

Priyatno D. 2012. Belajar Cepat Olah Data Statistik dengan SPSS. Mediakom. Yogyakarta
Riduwan. 2005. Belajar Mudah Penelitian Untuk Guru, Karyawan dan peneliti pemula, Bandung : Alfabeta.

Sueca NP, Primayatna IBG, Muliawan KS, Nada W, Wastika DN. 2001. Faktor-Faktor Derteminan Pengetahuan Dan Persepsi Masyarakat Tentang Bangunan Berlanggam Bali. Dimensi Teknik Arsitektur, Vol. 29, No 2.

Yulius YS, Maman S, Purwati. 2012. Persepsi Masyarakat Terhadap Usaha Tani Karet (Hevea brasiliensis) Di Desa Nanga Tekungai Kecamatan Serawai Kabupaten Sintang. Jurnal : Halaman 301-307 [14 April 2018]. 